Acta Theriologica 44 (3): 309-320, 1999.

PL ISSN 0001-7051

\title{
Ulnar dimensions and fossoriality in armadillos
}

\author{
Sergio F. VIZCAÍNO, Richard A. FARIÑA* and Gerardo V. MAZZETTA
}

Vizcaíno S. F., Farin̄a R. A. and Mazzetta G. V. 1999. Ulnar dimensions and fossoriality in armadillos. Acta Theriologica 44: 309-320.

Ulnar dimensions were measured in 14 species of armadillos (Xenarthra: Dasypodidae). An index of fossorial ability (IFA) was constructed, relating the length of the olecranon process to the remaining length of the ulna. For comparative purposes, the same measurements were taken in 14 other species of mostly South American mammals belonging to 3 orders and 11 families. The fossorial habits of these mammals were classified into 3 categories: (1) species mostly cursorial and non-digging; (2) species that often dig, but to which digging plays no essential part in their alimentary strategy and are not burrowers; and (3) species that are burrowers. IFA means of the studied mammal orders were compared using one-way analysis of variance on log-transformed data. Bivariate size allometry between ulnar dimensions and body mass was assessed by fitting (least squares and geometric mean) linear regressions of log-transformed data. It is concluded that the IFA discriminates among the species according to their fossorial habits within orders, but it is not equally useful in distinguishing fossorial species between orders. In armadillos, the relationships between ulnar dimensions and body mass are isometrical. Finally, the IFA is independent of body size.

CONICET, Departamento Científico Paleontología de Vertebrados, Museo de La Plata, Paseo del Bosque s/n, 1900 La Plata, Argentina, e-mail: vizcaino@museo.fenym.unlp.edu.ar (SFV); Departamento de Paleontología, Facultad de Ciencias, Iguá 4225, 11400 Montevideo, Uruguay, e-mail: fari a@fcien.edu.uy; mazzetta@fcien.edu.uy (RAF, GVM)

Key words: armadillos, Dasypodidae, fossoriality, ulna length, olecranon length, body size

\section{Introduction}

Armadillos are armoured mammals classified in the family Dasypodidae (Mammalia: Xenarthra). They are endemic of South America, and are widespread on the sub-continent, with some 20 living species (Wetzel 1985). One of them, Dasypus novemcinctus Linnaeus, 1758, reaches the southern USA. The group has a long history, their remains being known from the middle Palaeocene of South America (Patterson and Pascual 1972). Almost all species are, to some extent, fossorial. Digging is accomplished chiefly by a strong extension of their forearms.

This paper will test a hypothesis of the relationship between the fossorial habits of armadillos and their ulnar morphology. The relative length of the olecranon seemed to be potentially revealing, for it has a well-known association with fossorial habits (Shimer 1903). On the other hand, a short olecranon implies a

\footnotetext{
* To whom correspondence should be sent.
} 
selection for fast, rather than powerful, extension of the forearm (Fariña and Blanco 1996). Further, that feature is easily studied both in living and fossil species. Quantitative approaches have been developed in the past (Goldstein 1972, Hildebrand and Hildebrand 1994). However, they have not been extensively applied to South American mammals, nor has the problem of possible allometric effects been properly addressed. The family Dasypodidae is an appropriate group with which to test this hypothesis, because it is clearly monophyletic with species in a variety of sizes.

For comparative purposes, other mammals were considered in this study, involving other 14 species of mammals (mostly from South America) belonging to 3 orders and 11 families. Their habits range from cursorial to burrowing.

\section{Material and methods}

A total of 135 ulnae of several species belonging to 4 orders of (mostly) South American mammals were used (Table 1). In the case of armadillos (77 individuals belonging to 14 species), they represent the breadth of systematic diversity of the group at the tribe or subfamily level, following the classification proposed by Scillato-Yané (1980). Also, these animals range through three orders of magnitude in body mass from the $120 \mathrm{~g}$ pygmy armadillo Chlamyphorus truncatus Harlan, 1825 to the almost $50 \mathrm{~kg}$ giant armadillo Priodontes maximus (Kerr, 1792). The species used in this study were housed in the collections of the institutions listed in Appendix 1.

The fossorial habits of the animals studied were classified into 3 categories, namely mostly cursorial (sensu Jenkins 1971 and Stein and Casinos 1997: "cursorial mammals are those terrestrial quadrupeds that posses vertically-oriented limbs which move in a parasagittal plane, regardless of the gait being employed") and non-digging mammals (category 1); species that often dig, but to which digging plays no essential part in their alimentary strategy and are not burrowers (category 2); and species that are burrowers or that feed on termites or ants (category 3 ), as in both cases the digging movements of the forearm are the same, namely, a strong extension of the forearm. The choice for including a particular species in one of those three categories was accomplished according to data gathered from the literature (for instance, Nowak 1991) and from personal field observations. The naked-tailed armadillos Cabassous spp. and the pygmy Chlamyphorus truncatus have extremely fossorial habits (Nowak 1991). The giant armadillo Priodontes maximus is considered a powerful and rapid digger, and shelters in burrows of its own construction (Nowak 1991).

The three-banded armadillo Tolypeutes matacus (Desmarest, 1804) is the most cursorial within the family. Nowak (1991) states that this species does not seem to dig holes.

Those armadillos of the category 2 belong to the subfamilies Dasypodinae and Euphrachtinae. All these species for which habits are known have the average fossorial habits expected for the members of the group. However, this can only be tentatively said about Dasypus kappleri Krauss, 1862, because the habits of this species are not well known.

In Carnivora, the maned wolf Chrysocyon brachyurus (Illiger, 1815) and Geoffroy's cat Felis geoffroyi d'Orbigny and Gervais, 1842 are non-diggers. The grey fox Dusicyon gymnocercus (Fischer, 1814) has been reported to have its dens in burrows made by other animals, such as viscachas and armadillos (Nowak 1991). Finally, the skunks Conepatus spp. have the highest ratio and dig their own burrow as well as using burrows dug by other animals (Redford and Eisenberg 1989).

While the huemul Hippocamelus bisulcus (Molina, 1782) like other deer is completely cursorial, the wild boar Sus scrofa Linnaeus, 1758 has also the well-known digging habits of suids. To some extent, this is valid for the peccary Tayassu pecari (Link, 1795).

Within the five species of rodents under analysis, the Patagonian hare Dolichotis patagonum (Zimmerman, 1780) and the agouti Dasyprocta punctata Gray, 1842 are cursorial mammals (Nowak 1991). The intermediate behaviour is represented by the coypo Myocastor coypus (Molina, 1782). For 
Table 1. Untransformed measurements of bones, index of fossorial ability (IFA, as explained in the text), body mass and habits (as discussed in text) for some mammals. When appropriate, values are given as mean $\pm \mathrm{SD}$.

\begin{tabular}{|c|c|c|c|c|c|}
\hline Taxon & $\begin{array}{l}\text { Ulnar length } \\
(\mathrm{mm})\end{array}$ & $\begin{array}{l}\text { Olecranon length } \\
(\mathrm{mm})\end{array}$ & $\begin{array}{r}\text { IFA } \\
(n)\end{array}$ & $\begin{array}{l}\text { Body mass } \\
(\mathrm{kg})\end{array}$ & Habits \\
\hline Tolypeutes matacus & $49.4 \pm 4.9$ & $17.0 \pm 1.5$ & $0.53 \pm 0.04(4)$ & 1.53 & 1 \\
\hline Dasypus hybridus & $52.9 \pm 2.7$ & $20.6 \pm 1.2$ & $0.64 \pm 0.03(6)$ & 2.04 & 2 \\
\hline Dasypus novemcinctus & $68.7 \pm 3.5$ & $26.7 \pm 2.1$ & $0.64 \pm 0.06$ & 3.30 & 2 \\
\hline Dasypus kappleri & $93.2 \pm 2.9$ & $36.1 \pm 2.0$ & $0.64 \pm 0.05$ & 10.60 & $?$ \\
\hline Euphrachtus sexcinctus & $70.3 \pm 4.3$ & $27.9 \pm 4.0$ & $0.66 \pm 0.07(14)$ & 8.19 & 2 \\
\hline Chaetophactus vellerosus & 42.7 & 16.5 & $0.63(1)$ & 1.10 & 2 \\
\hline Chaetophactus villosus & $63.4 \pm 2.8$ & $25.2 \pm 2.7$ & $0.68 \pm 0.16$ & 4.50 & 2 \\
\hline Zaedyus pichiy & $44.4 \pm 0.21$ & $16.1 \pm 0.2$ & $0.57 \pm 0.01(2)$ & 1.74 & 2 \\
\hline Cabassou; chacoensis & 48.6 & 27.1 & $1.26(1)$ & 1.55 & 3 \\
\hline Cabassous centralis & $55.4 \pm 4.6$ & $26.6 \pm 3.6$ & $0.92 \pm 0.14$ & 3.80 & 3 \\
\hline Cabassou; unicinctus & $57.6 \pm 8.4$ & $27.9 \pm 2.8$ & $0.96 \pm 0.12(7)$ & 3.50 & 3 \\
\hline Cabassous tatouay & 68.7 & 31.4 & $0.84(1)$ & 6.20 & 3 \\
\hline Priodontes maximus & $132.6 \pm 4.0$ & $62.8 \pm 6.8$ & $0.91 \pm 0.15(10)$ & 45.19 & 3 \\
\hline Chlamypioorus truncatus & $22.2 \pm 0.1$ & $11.9 \pm 0.1$ & $1.15 \pm 0.04(2)$ & 0.12 & 3 \\
\hline Conepatus chinga & 62.0 & 13.5 & $0.28(1)$ & - & 2 \\
\hline Conepatus sp. & $60.1 \pm 6.7$ & $12.8 \pm 2.0$ & $0.27 \pm 0.03(7)$ & - & 2 \\
\hline Felis geofroyi & $110.8 \pm 23.5$ & $14.3 \pm 1.6$ & $0.15 \pm 0.03$ & - & 1 \\
\hline Chrysocyen brachyurus & $320.4 \pm 50.0$ & $28.7 \pm 3.1$ & $0.10 \pm 0.01(9)$ & - & 1 \\
\hline Dusicyon gymnocercus & $136.4 \pm 2.3$ & $17.1 \pm 1.0$ & $0.14 \pm 0.01(8)$ & - & 2 \\
\hline Hippocanelus bisulcus & 270.0 & 55.0 & $0.26(1)$ & - & 1 \\
\hline Sus scrofe & 185.0 & 70.0 & $0.61(1)$ & - & 2 \\
\hline Tayassu pecari & 128.0 & 36.0 & $0.39(1)$ & - & 2 \\
\hline Dasyproca sp. & 72.5 & 11.5 & 0.19 (1) & - & 1 \\
\hline Dasyprocia punctata & $80.7 \pm 4.2$ & $14.0 \pm 0.8$ & $0.21 \pm 0.02(6)$ & - & 1 \\
\hline Dolichoti: patagonum & $170.0 \pm 5.3$ & $25.0 \pm 2.1$ & $0.17 \pm 0.01(6)$ & - & 1 \\
\hline Myocastor coypus & $91.3 \pm 15.2$ & $18.9 \pm 4.4$ & $0.26 \pm 0.03(2)$ & - & 2 \\
\hline Lagostomus maximus & $86.6 \pm 7.4$ & $18.2 \pm 4.3$ & $0.27 \pm 0.06(7)$ & - & 3 \\
\hline Hydrochceris hydrochaeris & $166.8 \pm 7.8$ & $46.3 \pm 2.5$ & $0.39 \pm 0.01$ & - & 1 \\
\hline
\end{tabular}

shelter, tiis rodent takes over the hole of another animal or constructs its own burrow. The latter may be a singe tunnel or a complex system containing passages that extend $15 \mathrm{~m}$ or more and chambers (Nowak 1991). Viscacha Lagostomus maximus (Desmarest, 1817) constructs extensive burrow systems, called "viscacheras", some of which are used for centuries and may cover up to $600 \mathrm{~m}^{2}$. To construct these burows some $8 \mathrm{~m}^{3}$ have to be moved, which illustrates the digging ability of this species (Nowak 1991). Fnally, the capybara Hydrochaeris hydrochaeris (Linnaeus, 1766) is not known to dig whatsoever.

The neasurements taken on this material are shown in Fig. 1. Total ulnar length (UL) was measurec from the tip of the olecranon to the tip of the styloid process, and olecranon length (OL) as the distance from the tip of the olecranon to a point the middle of the semilunar notch. Ulnar and olecranor lengths were measured in cleaned bones of adult individuals with appropriate callipers to the nearest $0.1 \mathrm{~mm}$. Also, lengths were measured on the right forearm whenever the landmarks were intact. If they were not, the left forearm was used instead. 


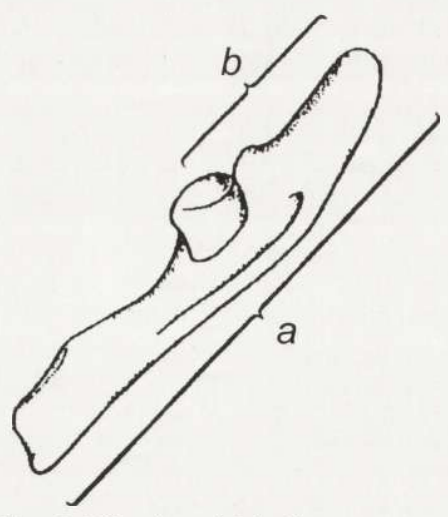

Fig. 1. Way in which the measurements of total ulnar length (UL, $a$ ) and olecranon length $(\mathrm{OL}, b)$ were obtained.
The index of fossorial ability (IFA) was obtained by dividing OL by the subtraction UL minus OL. This index describes the relative mechanical advantage of the triceps muscle (Hildebrand and Hildebrand 1994). This muscle is the main extensor of the forearm, and is extensively used by those mammals that dig with movements of the whole arm.

Univariate statistics used are described in standard textbooks (Sokal and Rohlf 1981) and listed for each species in Table 1. IFA means of the studied mammal orders were compared using one-way analysis of variance (ANOVA) on log-transformed data and Scheffe's multiple-range test at the 0.05 level of significance. The same analyses were computed among subfamilies of Dasypodidae and also among families in each of the remaining orders. Data were log-transformed to stabilize the variance. The Scheffe's test was used because it is conservative, requiring larger differences between population means for significance than most multiple-comparison methods.

Bivariate size allometry was assessed by fitting the following allometric model for two random variables $X$ and $Y$ (Huxley 1932, Gould 1966, 1971, notation follows Ricker 1984): $Y=a X^{b}$. This power equation was linearised by log-transformation (base 10) into $\log Y=\log a+b \log X$. Considerable controversy surrounds the statistical methods used to estimate the two parameters, $\log a$ (intercept) and $b$ (slope or allometric coefficient), although most applications have been based on simple (least squares) linear regressions of $\log Y$ on $\log X$. This method is easy to use and permits calculation of standard error (SE) of the slope estimate but assumes, usually wrongly, that only $Y$ is subject to measurement error or natural variability or both. Geometric mean regressions (GMR) provide a slope which is the geometric mean of the estimate derived from $\log Y$ (linearly) regressed on $\log X$ and the inverse of that derived from regressing $\log X$ on $\log Y$ (Ricker 1973, 1984). Both methods were employed (see Swartz and Biewener 1992) in order to test the relationship of forearm skeletal dimensions and body size in armadillos. Hence, the following regressions of log-transformed data were calculated: ulnar and olecranon length versus body mass, and olecranon length versus ulnar length (also performed for comparison in each of the remaining mammal orders considered). Each slope (using the $95 \%$ confidence limits) was tested against the null hypothesis of isometry, ie the maintenance of geometric similarity with size increase: $\beta=1 / 3$ for osteometric lengths against body mass, and $\beta=1$ for olecranon length as compared to ulnar length. Also, the relationship of IFA and body size in armadillos was analysed.

Body masses were not available for all the studied individuals. Nevertheless, the masses of most species belonging to the family Dasypodidae were obtained and averaged from the literature (Rood 1970, McNab 1980, Wetzel 1985, Fariña and Vizcaíno 1997). The mass of Cabassous chacoensis Wetzel, 1980 was estimated by scaling down that of C. tatouay (Desmarest, 1804) (see Redford and Eisenberg 1989).

The bivariate relationships between IFA and the fossorial categories (considering all the species studied or the species of each order separately) were explored with least-squares linear regressions of log-transformed data.

We use nomenclature as in general books on mammals, such as Nowak (1991).

\section{Results}

ANOVA and Scheffe's multiple-range test showed that IFA means differ significantly among all orders studied $(F=232.65$, df $=3,131, p<0.0001)$. Moreover, the variability among orders was greater than the variability within each 
order, as evidenced by their relative sums of squares (59.7 and 11.2, respectively). IFA values of the Dasypodidae were the highest, with a mean ( \pm SD) of $0.74 \pm 0.18$ (range $0.47-1.26, n=77$ ). Among them, the three-banded armadillo Tolypeutes matacus is in the lowest extreme, while the naked-tailed Cabassous chacoensis and the pigmy armadillo Chlamyphorus truncatus are the species whose values are the highest. The rest of the dasypodids yielded intermediate figures.

The species belonging to order Carnivora shows the lowest IFA values, with a mean of $0.17 \pm 0.07$ (range $0.08-0.32, n=29$ ). The skunks Conepatus spp. have the highest values, whereas the index for the maned wolf Chrysocyon brachyurus is the lowest. The grey fox Dusicyon gymnocercus and the Geoffroy's cat Felis geoffroyi lie between them, and closer to the latter.

The studied species of Rodentia have higher IFA values than those observed in Carnivora, with a mean of $0.25 \pm 0.08$ (range $0.16-0.39, n=26$ ). The rodents range from the Patagonian hare Dolichotis patagonum and the agoutis Dasyprocta spp. in the lower extreme to the capybara Hydrochaeris hydrochaeris at the upper limit. The coypo Myocastor coypus and the viscacha Lagostomus maximus are at an intermediate level.

IFA values of the studied species of Artiodactyla were higher than those of Rodentia, with a mean of $0.42 \pm 0.18$ (range $0.26-0.61, n=3$ ). Among them, the huemul Hippocamelus bisulcus has the lowest value, the wild boar Sus scrofa, the highest and the peccary Tayassu pecari has an intermediate value.

ANOVA and Scheffe's test performed on Dasypodidae showed that IFA means of the subfamilies were significantly different $(F=44.61$, df $=4,72, p<0.0001)$, except for Dasypodinae and Euphrachtinae. In Carnivora, IFA means differ significantly among all families studied $(F=59.75, \mathrm{df}=2,26, p<0.0001)$. Similar results were observed in Rodentia $(F=24.16, \mathrm{df}=4,21, p<0.0001)$, except for Myocastoridae and Chinchillidae. It was not possible to compare IFA means of the three families of Artiodactyla due to the very low number of specimens ( $n=1$, each family).

In armadillos, the size-allometric relationship between ulnar length and body mass exhibits isometry $(b=0.30, \mathrm{SE}=0.02, p>0.10, r=0.98, n=14$, Fig. $2 \mathrm{a})$. The same was observed for olecranon length versus body mass $(b=0.29, \mathrm{SE}=0.04, p>$ $0.25, r=0.92, n=14$, Fig. $2 \mathrm{~b}$ ). Also, the relationship between olecranon length and ulnar length shows no change of shape with size increase $(b=0.94, \mathrm{SE}=0.10, p>$ $0.50, r=0.93, n=14)$. The same is valid for the species of Rodentia $(b=1.16, \mathrm{SE}=$ $0.30, p>0.60, r=0.89, n=6$ ). In Carnivora a strong negative allometry was observed between these forearm dimensions $(b=0.46$, SE $=0.08, p<0.01, r=$ $0.96, n=5$ ). For the species of Artiodactyla, olecranon length was not significantly correlated with ulnar length $(r=0.62, n=3, p>0.55)$, although the very small sample could obscure the relationship. Considering all the species studied, the slope of the regression between olecranon length and ulnar length is significantly different from isometry $(b=0.50, \mathrm{SE}=0.13, p<0.001, r=0.59, n=28$, Fig. 3 ). In all the analysed size-allometric relationships, but in the last two cases, very similar 

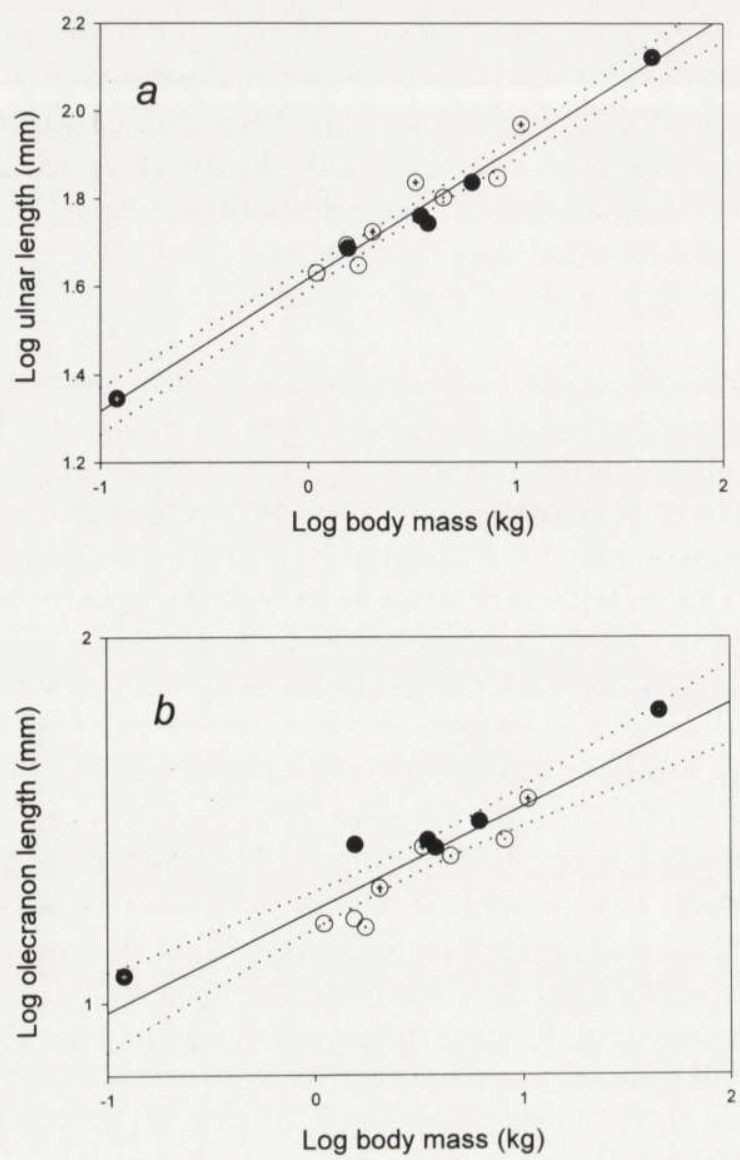

Fig. 2. Graph showing allometric relations of some forearms dimensions in armadillos: a) log ulnar length $(\mathrm{mm})$ vs. log body mass $(\mathrm{kg})$; b) log length of olecranon $(\mathrm{mm})$ vs. log body mass $(\mathrm{kg})$. Solid line is the regression, and dotted lines are the confidence interval at the $95 \%$ level. Open circle: Tolypeutes matacus; solid circles: Cabassous chacoensis, C. centralis, C. tatouay and C. unicinctus; dotted circles Euphrachtus sexcinctus, Chaetophrachtus vellerosus, C. villosus and Zaedyus pichiy; solid dotted circle Priodontes maximus; crosshaired circles Dasypus hybridus, D. novemcinctus and D. kappleri; solid crosshaired circle: Chlamyphorus truncatus.

results were obtained using the slope of a geometric mean regression as a consequence of the usually high correlation coefficients. In the last case, since the correlation coefficient is not very high, the slope calculated after the geometric mean regression method had a different value $(b=0.84)$, and thus, the isometric hypothesis would cannot be rejected $(p>0.10)$. In armadillos, IFA values were not significantly correlated with body mass $(r=-0.14, n=14, p>0.60)$.

On the other hand, and considering all the species studied, the increase in IFA values was significantly and positively correlated with the fossorial categories 




Fig. 3. Graph showing allometric relations of log length of olecranon ( $\mathrm{mm}$ ) vs. log ulnar length (mm). Solid line is the regression, and dotted lines are the confidence interval at the $95 \%$ level. Open squares: Conepatus chinga and $C$. sp.; solid squares: Chrysocyon brachyurus and Dusicyon gymnocercus; dotted square: Felis geoffroyi; open triangle: Hippocamelus bisulcus; solid triangle: Tayassu pecari; dotted triangle: Sus scrofa; inverted open triangles: Dasyprocta punctata and D. sp.; inverted solid triangle, Lagostomus maximus; inverted dotted triangle: Dolichotis patagonum; inverted crosshaired triangle: Myocastor coypus; inverted solid dotted triangle: Hydrochaeris hydrochaeris. Other symbols as in Fig. 2.

$(b=1.20, \mathrm{SE}=0.12, r=0.65, n=131, p<0.00001)$. Similar results were observed in Dasypodidae $(b=0.67, \mathrm{SE}=0.07, r=0.77, n=73, p<0.00001)$ and Carnivora $(b=0.79, \mathrm{SE}=0.16, r=0.68, n=29, p<0.0001)$. When all the species of Rodentia were considered, the correlation was non-significant $(r=0.24, n=26, p>0.20$ ). However, if the capybara $H$. hydrochaeris is excluded, the increase in IFA values turns out to be significantly and positively correlated with the fossorial categories $(b=0.30, \mathrm{SE}=0.07, r=0.70, n=22, p<0.001)$. In the species of Artiodactyla, IFA values were not significantly correlated with fossorial categories $(r=0.85, n=3, p$ $>0.35$ ), although this lack of relationship could be again attributed to the low $n$.

\section{Discussion}

As expected, the results obtained indicate that the trend to fossoriality in living armadillos is correlated with the relative development of the olecranon process. This development is interpreted as an improvement of the mechanical advantage of the triceps muscle, the forearm extensor.

We took the ratio of the length of the olecranon to total ulnar length to construct an index of fossorial ability. Though there are some caveats to this approach, for instance, hardness of the substrate and differential strength of the muscle itself (respectively influencing the output and input forces), it seemed to be useful to appreciate the fossorial abilities in those species through this character. 
It could be argued that another possible problem posed by this approach might be size dependence of IFA. In an earlier research, we included the large extinct species Propraopus grandis (Fariña and Vizcaíno 1997). In that paper, ulnar dimensions in armadillos were observed to depart from the geometric similarity, as predicted by Casinos et al. (1993) for other fossorial mammals. Geometric similarity predicts that linear dimensions vary in regard to body mass with an exponent (or a coefficient, if logarithms are taken) of $1 / 3$, surfaces with an exponent of $2 / 3$ and volumes with an exponent of 1 . In log-log scale, ulnar length varied with regard to body mass with a coefficient of slightly less than $1 / 3$. In the present paper (which excludes the large fossil species $P$. grandis and includes the small to average-sized living species of the genus Cabassous as well as Euphractus sexcinctus (Linnaeus, 1758), the theoretical value $1 / 3$ falls within the $95 \%$ confidence interval of the slope of ulnar length to body mass $(0.26 \leq \beta \leq 0.35)$. Hence, the slope calculated for this relationship $(b=0.30)$ did not differ significantly from the theoretical one of $1 / 3(p>0.10)$. In other words, its variation is explained by geometric similarity.

The length of the olecranon also tends to vary in regard to body mass according to geometric similarity. The slope of the calculated regression is 0.29 , and hence this value did not differ significantly from $1 / 3(p>0.25)$.

Moreover, the relative olecranon length also does not seem to be affected by allometric relationships; olecranon length varies with regard to total ulnar length with a coefficient statistically indistinguishable from $1(p>0.50)$ when armadillos of a broad range of sizes were studied. Thus, it can be safely stated that IFA does not vary with body mass in armadillos, which was corroborated when this index was regressed against body mass.

This result is rather surprising. Positive allometric relationship between the effective mechanical advantage for the elbow (defined as the ratio muscle moment arm - which is equivalent to our olecranon length - to the moment arm of the ground reaction force - which is ulnar length plus manus length) and body mass have been found in seven generalized mammals (Biewener 1989); the slope of the appropriate regression was 0.26 . Also, Alexander et al. (1981) found a positive allometric relationship $(b=0.46)$ between the triceps moment arm and body mass for a large set of mammals. For the mammals studied in the present research, the relationship between olecranon length and ulnar length is isometric $(p>0.50)$, except for the Carnivora, in which this relationship is allometrically negative ( $p<$ 0.01 ). Such incongruity can be more easily explained in both armadillos and South American (caviomorph) rodents, two digging groups that were not considered in the cited papers. As for the Carnivora, the results obtained remain unexplained.

The naked-tailed armadillo Cabassous chacoensis and the pygmy Chlamyphorus truncatus show the higher values of IFA (Table 1) and are the better equipped for fossoriality. Their habits are congruent with these results. The most cursorial armadillo, the three-banded Tolypeutes matacus, shows the lowest IFA of the family. Those armadillos of the category 2 belong to the subfamilies Dasypodinae 
and Euphrachtinae, and also have intermediate values for IFA. However, this congruence can only be tentatively said about Dasypus kappleri, because the habits of this species are not well known. The IFA predicts the same fossorial habits for this species as those of the other two cogeneric species studied here.

The situation is not different in the other mammalian groups chosen for testing. Indeed, within the group, those mammals of habits known to be less fossorial tend to have lower values of IFA, and vice versa.

In the Carnivora, the species showing the lowest values, i.e. the maned wolf is a non-digger. The grey fox and the Geoffroy's cat have slightly higher values, and the skunks Conepatus spp. have the highest ratio.

The wild boar has a higher value than the huemul, in agreement with the well-known digging habits of suids and the cursorial adaptation of deer.

Within the six species of rodents under analysis, the cursorial Patagonian hare and the agoutis are at the lowest extreme of IFA. The intermediate situation is represented by the coypo. Within rodents, the viscacha shows the second highest value. In this order, the capybara is the clear exception to the congruence found so far between the values of IFA and habits, as this giant rodent is not reported to be a digger. If, for the sake of the argument, the capybara is considered as belonging to category 2 , the increase in IFA values for rodents turns out to be significantly and positively correlated with the fossorial categories $(b=0.38, \mathrm{SE}=0.10, r=0.63, n=$ $26, p<0.001$ ). This higher than expected IFA of $H$. hydrochaeris might be related to the swimming habits in this species, although this has not been appropriately studied, and it is out of the scope of this paper.

Goldstein (1972) studied some unspecialised burrowing mammals, as sciurids and rabbits. His results are comparable to ours.

However, between the orders, the index seems to be less useful for identifying species in regard to their digging habits, as those species of similar habits but belonging to different orders tend to resemble their nearer relatives in their values of IFA. Each group appears to have its own distinctive range of IFAs. For instance, the viscacha, a powerful digger, shows a lower figure than does the cursorial three banded armadillo. This paradox might be explained by the proposal that the phylogenetic history poses constraints that become stronger at higher taxonomic levels (Richman and Price 1992).

As can be observed in Fig. 2a, Dasypus novemcinctus has a longer ulna than expected. However, as its olecranon is also longer than expected (Fig. 2b), its IFA falls to average values for an armadillo. On the other hand, Cabassous centralis (Miller, 1899) show a very short ulna for its size, and the olecranon is as long as expected for an armadillo of its size. Its cogeneric C. chacoensis seems to have relied on a different evolutionary improvement of the mechanical advantage of the triceps musde; its ulna is the size expected for an armadillo of its size, while the olecranon is much longer than expected.

In Fig. 3, those armadillos of the subfamily Priodontinae tend to have longer olecranon for their total ulnar length, as well as the boar and the capybara. On the 
other extreme, the Geoffroy's cat, the agoutis and the grey fox are among the mammals that show shorter olecranon for their total ulnar length.

Summing up, the index of fossorial ability was effective in identifying diggers, either in armadillos or other mammals. Within every group, the animals that are known to be more specialized for digging show higher values, and the opposite is true for those of more cursorial habits. Between the orders studied, IFA was not as good a predictor of digging habits.

This approach opens the opportunity to infer fossorial habits in fossil species for which the forearm skeleton is sufficiently known, particularly those belonging to the members of the varied fauna of extinct South American armadillos (Vizcaíno and Fariña 1997). Moreover, it would be most interesting to apply this technique more thoroughly to other monophyletic groups of forearm-digging mammals. Also, the regression relating IFA to fossorial categories could be used for inverse prediction of potential digging habits in extinct armadillos. If conversions of IFA to fossorial category are the sole concern, the geometric mean line should be used for estimating the fossorial category from IFA, and vice versa.

Acknowledgements: We are grateful to Federico Achaval and Alfredo Le Bas (FC), Ross McPhee (AMNH), Bruce Patterson (FMNH), Guillermo Rougier and Olga Vaccaro (MACN), Richard Thorrington (NMNH) and Diego Verzi (MLP-DZV) for access to the respective collections. Enrique Lessa and Leo Joseph made important suggestions. One of us (SFV) obtained the measurements at the FMNH thanks to a Field Museum Scholarship. This paper is inscribed in the project PIA-Conicet 6811/96.

\section{References}

Alexander R. McN., Jayes A. S., Maloiy G. M. O. and Wathuta E. M. 1981. Allometry of the leg muscles of mammals. Journal of Zoology, London 194: 539-552.

Biewener A. A. 1989. Scaling body support in mammals: limb posture and muscle mechanics. Science 245: 45-48.

Casinos A., Quintana C. and Viladiu C. 1993. Allometry and adaptation in the long bones of a digging group of rodents (Ctenomyinae). Zoological Journal of the Linnean Society 107: 107-115.

Fariña R. A. and Blanco R. E. 1996. Megatherium, the stabber. Proceedings of the Royal Society B, 263: $1725-1729$.

Fariña R. A. and Vizcaíno S. F. 1997. Allometry of the leg bones of some living and extinct armadillos (Dasypoda). Zeitschrift für Säugetierkunde 62: 65-70.

Goldstein B. 1972. Allometric analysis of relative humerus width and olecranon length in some unspecialized burrowing mammals. Journal of Mammalogy 53: 148-156.

Gould S. J. 1966. Allometry and size in ontogeny and phylogeny. Biological Reviews 41: 587-640.

Gould S. J. 1971. Geometric similarity in allometric growth: A contribution to the problem of scaling in the evolution of size. The American Naturalist 105: 113-136.

Hildebrand M. and Hildebrand V. 1994. Analysis of vertebrate structure, 4th Edition. John Wiley \& Sons, Inc., New York: 1-672.

Huxley J. S. 1932. Problems of relative growth. Methuen \& Co. Ltd., London: 1-276.

Jenkins F. A. 1971. Limb posture and locomotion in the Virginia opossum (Didelphis marsupialis) and in other non-cursorial mammals. Journal of Zoology, London 165: 303-315.

McNab B. K. 1980. The physiological signification of body size. Journal of Mammalogy 61: 606-627.

Nowak R. M. 1991. Walker's mammals of the world. Johns Hopkins University Press, Baltimore: $1-1629$. 
Patterson B. and Pascual R. 1972. The fossil mammal fauna of South America. [In: Evolution, Mammals and Southern Continents. A. Keast, F. C. Erk and B. Glass, eds]. State University of New York Press, Albany: 247-309.

Richman A. D. and Price T. 1992. Evolution of ecological differences in the Old World leaf warblers. Nature 355: 817-821.

Redford K. H. and Eisenberg J. F. 1989. Mammals of the Neotropics. The Southern Cone. Vol. 2. University of Chicago Press, Chicago: 1-430.

Ricker W. E. 1973. Linear regressions in fishery research. Journal of Fisheries Research Board of Canada 30: 409-434.

Ricker W. E. 1984. Computation and uses of central trend lines. Canadian Journal of Zoology 62: 1897-1905.

Rood J. P. 1970. Notes on the behavior of the pigmy armadillo. Journal of Mammalogy 51: 179.

Scillato-Yané G. J. 1980. Catálogo de los Dasypodidae fósiles (Mammalia, Edentata) de la República Argentina. Actas II Congreso Argentino de Paleontología y Bioestratigrafía y I Congreso Latinoamericano de Paleontología 3: 7-36.

Shimer H. W. 1903. Adaptation to arboreal, aquatic and cursorial habits in mammals. III. Fossorial adaptation. The American Naturalist 37: 819-825.

Sokal R. R. and Rohlf F. J. 1981. Biometry, 2nd ed. W. H. Freeman and Company, New York: 1-301.

Stein B. R. and Casinos A. 1997. What is a cursorial mammal? Journal of Zoology, London 242: 185-192.

Swartz S. M. and Biewener A. A. 1992. Shape and scaling. [In: Biomechanics (structures and systems): a practical approach. A. A. Biewener, ed]. Oxford University Press, Oxford: 21-43

Vizcaíno S. F. and Farin̄a R. A. 1997. Diet and locomotion in Peltephilus: A new view. Lethaia 30: 79-86.

Wetzel R. H. 1985. Taxonomy and distribution of armadillos, Dasypodidae. [In: Evolution and ecology of armadillos, sloths and vermilingua. G. G. Montgomery, ed]. Smithsonian Institution Press, Washington \& London: 23-46.

Received 24 October 1997, accepted 15 April 1999. 
Appendix 1. The measurements were taken in the specimens listed below.

Abbreviations: Museo Argentino de Ciencias Naturales "Bernardino Rivadavia" (MACN), Buenos Aires, Argentina; Departamento Científico de Paleontología de Vertebrados of the Museo de La Plata, Argentina (MLP and MLP-DPV, respectively fossils and Recent animals); Departamento Científico de Zoología, same institution (MLP-DZV); Field Museum of Natural History, Chicago, USA (FMNH); National Museum of Natural History, Smithsonian Institution, Washington D.C., USA (NMNH); American Museum of Natural History, New York, USA (AMNH); Facultad de Ciencias, Montevideo, Uruguay (FC-DPVC, FC-FA, Departamento de Zoología Vertebrados and Federico Achaval's personal collection, respectively).

Tolypeutes matacus (Dasypodidae, Tolypeutinae); MLP-DPV 13, AMNH 248394, FMNH 24570, FMNH 122233; Dasypus hybridus (Desmarest, 1804) (Dasypodidae, Dasypodinae) MLP-DPV 65, FC-DPVC 108, FC-FA 658, AMNH 33258, AMNH 205707, AMNH 205706; Dasypus novemcinctus (Dasypodidae, Dasypodinae): MLP-DPV 80, AMNH 33265, AMNH 13268, AMNH 13327, AMNH 13268, AMNH 133357, AMNH 133355, AMNH 133358, AMNH 133365, AMNH 133371, AMNH 133361f, NMNH 49598, 339668, FMNH 39307, FMNH 60493, FMNH 60468, FMNH 60682; Dasypus kappleri (Dasypodidae, Dasypodinae): AMNH 267011, AMNH 36251, AMNH 26701, NMNH 256761; Euphractus sexcinctus (Dasypodidae, Euphrachtinae): AMNH 205685, AMNH 80098, AMNH 90424, AMNH 90108, AMNH 100075, AMNH 100279, AMNH 61803, AMNH 133296, AMNH 13302, NMNH 258603, NMNH 259462, NMNH 257968, NMNH 256115, FMNH 52051; Chaetophractus villosus (Desmarest, 1804) (Dasypodidae, Euphrachtinae): MLP-DPV 48, AMNH 70173, NMNH 55411, NMNH 396655, NMNH 543430; Chaetophractus vellerosus (Gray, 1865) MLP-DPV 74; Zaedyus pichiy (Desmarest, 1804) (Dasypodidae, Euphrachtinae): FMNH 04817; Cabassous chacoensis (Dasypodidae, Priodontinae): MLP-DPV 60; Cabassous unicinctus (Linnaeus, 1758) (Dasypodidae, Priodontinae): AMNH 33318, AMNH 133319, AMNH 133314, AMNH 133336, AMNH 133334, AMNH 14862, NMNH 13422; Cabassous tatouay, AMNH 133317; Cabassous centralis (Dasypodidae, Priodontinae): AMNH 23441, NMNH 36315, NMNH 574499; Priodontes maximus (Dasypodidae, Priodontinae) MACN unnumbered, AMNH 30387, AMNH 208104, AMNH 130122, NMNH 299630, NMNH 270373, NMNH 261024, FMNH 25271, FMNH 72913, FMNH 60450; Chlamyphorus truncatus (Dasypodidae, Chlamyphorinae): MACN 471, NMNH 200362; Conepatus chinga (Molina, 1872) (Carnivora, Mustelidae): MLP-DZV 1015; Conepatus sp. (Carnivora, Mustelidae): AMNH 205848, AMNH 205843, AMNH 205842, AMNH 205848, AMNH 205834, AMNH 205844, AMNH 205850; Felis geoffroyi (Carnivora, Felidae) MLP-DZV 1037, FMNH 21290, FMNH 129394, FMNH 134485; Chrysocyon brachyurus (Carnivora, Canidae): MLP-DZV 88, AMNH 33941, AMNH 135724, AMNH 120999, AMNH 133940; Dusicyon gymnocercus (Carnivora, Canidae): MLP-DPV unnumbered, AMNH 205778, AMNH 205780, AMNH 205776, AMNH 205783, AMNH 205577, AMNH 205786, AMNH 205770, FMNH 44534, FMNH 283311, FMNH 27101, FMNH 101848; Hippocamelus bisulcus (Artiodactyla, Cervidae): MLP-DZV 1145; Sus scrofa (Artiodactyla, Suidae): MLP-DZV unnumbered; Tayassu pecari (Artiodactyla, Tayassuidae): FMNH 49848; Dolichotis patagonum (Rodentia, Caviidae): MLP-DZV 1079, AMNH 80123, AMNH 35301, FMNH 53719, FMNH 49231, FMNH 49213; Myocastor coypus (Rodentia, Myocastoridae): MLP-DZV 1172, FMNH 5617; Lagostomus maximus (Rodentia, Chinchillidae) MLP-DZV 27-IV-95-1, AMNH 262287, AMNH 100147, AMNH 70062, AMNH 70002, FMNH 53737, FMNH 53704; Hydrochaeris hydrochaeris (Rodentia, Hydrochoeridae): MLP-DZV 1085, AMNH 206440, FMNH 51636, FMNH 607335; Dasyprocta punctata (Rodentia, Dasyproctidae): MLP-DZV 1090, AMNH 61441, AMNH 15436, AMNH 23461, AMNH 23463, AMNH 23465, AMNH 23464; Dasyprocta sp. (Rodentia, Dasyproctidae): MLP-DZV unnumbered. 